https://helda.helsinki.fi

\title{
The structure of participants' turn-transition practices in aided conversations that use speech-output technologies
}

\section{Savolainen, Irina}

2020-01-02

Savolainen , I , Klippi , A , Tykkyläinen , T, Higginbotham , J \& Launonen , K 2020 , ' The structure of participants' turn-transition practices in aided conversations that use speech-output technologies ' , Augmentative and Alternative Communication , vol. 36 , no. 1 , pp. 18-30 . https://doi.org/10.1080/07434618.2019.1698654

http://hdl.handle.net/10138/325107

https://doi.org/10.1080/07434618.2019.1698654

unspecified

acceptedVersion

Downloaded from Helda, University of Helsinki institutional repository.

This is an electronic reprint of the original article.

This reprint may differ from the original in pagination and typographic detail.

Please cite the original version. 


\begin{abstract}
Using the concepts and principles of conversation analysis (CA), this paper examines the everyday unscripted spontaneous conversations between 4 boys who communicate with the aid of a speech-generating device (SGD), and their mothers. The analyses focused on describing the conversationalists' various actions in aided turn-transition processes resulting in a 33-part turntransition structure used to accomplish aided turn initiation. Despite the challenges to conversational progress, the participants did not consider the slow conversational speed a challenge. Both the mothers and their children were orientated to progression of the aided conversation by creating interaction practices to achieve successful turn-transitions. By understanding the structural characteristics of fluent aided conversations, it may be possible to develop communication strategies and device features that promote fluent interactions.

Keywords: Aided conversation; Conversation analysis; Interaction; Speech-generating device; Turn-transition
\end{abstract}


The Structure of Participant Turn-transition Practices in Aided Conversations That use Speech-Generating Devices

In virtually all spoken conversations, participants coordinate the progress of their interactions on a moment-by-moment basis by designing their talk to address perceived recipient needs within the current situational context (Schegloff, 2007). Furthermore, their interactional progress is carried out in the temporal and structural levels of interaction. When participants talk together, "someone's turn must always and exclusively be in progress" (Sacks, Schegloff, \& Jefferson, 1974, p. 697), temporally furthering the conversation. The accumulation of speaking turns — one following another — creates a structurally ordered sequence (Schegloff, 2007).

In conversations that involve the use of augmentative and alternative communication (AAC) devices, participants also exchange turns that are constructed in sequences and produced in a temporally organized fashion (Sigurd Pilesjö, 2013). However, many of these aided conversations are characterized by the slow pace of aided turn production, the asymmetrical participation by the interactants, and the aided speakers' overtly co-constructed contributions over a series of turns (Clarke, 2016; Higginbotham \& Wilkins, 1999; Noren, Samuelsson, \& Plejert, 2013). When these phenomena are combined, they can significantly affect the progress of aided conversations, and impact the participants' perceptions of their parity during their interaction (Blackstone, Williams, \& Wilkins, 2007).

Conversation Analysis (CA) is the descriptive, microanalytic study of social interaction. Research in this field asserts that the progress of conversation is ensured by structuring it according to the systematic rules of turn-taking and the organization of turns in sequences (Hayashi, 2013; Levinson, 2013; Sacks et al., 1974; Ten Have, 2007). A sequence is a series of turns (Schegloff, 2007). A basic sequence consists of two turns that are produced by different 
speakers, consecutively and are ordered as a first pair part (e.g., question) that creates a place for the second pair part (e.g., answer) to occur. Conversation analysts have identified hundreds of sequence variations that are implicitly oriented to and used by participants within a speaking culture (Schegloff, 2007).

Participants coordinate their turn-taking activities by observing the flow of conversation and determining when a relevant point arises for a turn-transition to occur. During these transition relevant places in a conversation, both participants usually have an opportunity to take a turn. For example, after one speaker talks, their interlocutor may elect to take their speaking turn, or the first speaker may continue his or her turn. In either case, the transition between turns typically occurs smoothly, with minimal delay or overlap between participants' speech. To accomplish this feat of turn-taking coordination, the speaker usually produces a variety of signals through prosody, syntax, gaze, and social action that the interlocutor uses to anticipate when the next relevant point will occur for a turn-transition (Enfield, 2017, Levinson, 2013). Potential speakers also display their intention to speak when they are ready to take their turn by producing pre-beginnings, such as by taking an in-breath, through throat clearing, lip-parting, and gazing at their recipient (Schegloff, 1996).

The ability to coordinate turn-taking quickly and precisely is a ubiquitous and universal feature of spoken language (Enfield, 2017; Sacks et al., 1974). However, speakers may sometimes forgo the option of taking a turn, even though they have not closed the conversation (Sacks et al., 1974). A prolonged delay may arise because some now-relevant activity is completed, such as examining some reading material that is relevant to the conversation, or due to other ongoing activities, such as eating. If no cause if readily visible for the prolonged delay, participants may treat them as conspicuous by displaying disinterest in speaking, protracting the 
end of sequences, such as by producing minimal responses, or by focusing their attention on the environment (Enfield, 2017; Hoey, 2015).

Aided conversations are frequently characterized by overtly co-constructed turns and collaborative actions that involve aided and speaking partners (Noren, Samuelsson et al., 2013; Sigurd Pilesjö, 2013). Primary factors that influence the course of aided interactions are the participants' competencies, roles, relationships, situational demands, specific features of AAC technologies, and the need to make progress (Engelke \& Higginbotham, 2013; Higginbotham, Fulcher, \& Seale, 2016; Noren, Samuelsson et al., 2013).

The conversational pace of aided conversations is considerably slower than in spoken conversations. During interactions that are mediated by a speech-generating device (SGD), the silent gaps between turns and the elements within turns are often long due to the time needed to compose an utterance (Clarke, Bloch, \& Wilkinson, 2013). These delays can lead to a partner's disattention, forgetting, and misunderstanding, which can subsequently impede the aided communicator's ability to enter the conversation and sustain progress in the interaction (Higginbotham \& Wilkins, 1999). If the conversants are familiar to one another, they may display a better understanding of how to advance a conversation than do unfamiliar partners (Batorowitz, Campbell, von Tetzchner, King, \& Missiuna, 2014; Enfield, 2013).

Participants often address the aforementioned problems associated with aided conversations by engaging in a variety of interaction practices to diminish or circumvent these challenges (Higginbotham \& Wilkins, 1999). Adult aided speakers demonstrate their awareness of temporal constraints by adopting different body-based and AAC-based strategies to minimize communication problems. These include their use of gestures or vocalizations to issue short, in time utterances, or to prepare a longer, delayed utterance silently before 'speaking' it out loud 
(Higginbotham et al., 2016). During children's aided conversations, the most often reported strategies that aided communicators adopt to stay in time are their use of short and imprecise utterances (see Binger \& Light, 2008).

Previous research has indicated that the demand for the progress of children's aided conversation usually lies with the speaking partner (Noren, Samuelsson et al., 2013). Clarke $(2005,2016)$ has described the commonly observed frame of an aided conversation as a sequence, whereby the first pair part is produced using natural speech by the partner, and the second pair part is an aided turn that is constructed by the aided communicator. This sequence usually occurs as a question - minimal answer pair. The positioning of the aided utterance as a second pair part contextualizes the aided communicator's contribution of the aided communicator as an answer to the question, which both facilitates interpretation of its meaning and furthers turn progression (Clarke \& Wilkinson, 2008).

During aided conversations, the partner also has multiple opportunities to display their active orientation to the delay by producing meta-interactional prompts that appear to complete the composition of the ongoing aided utterance, re-allocate the turn to the aided speaker (e.g., "ask me a question"), comment on performance (e.g., "Yes, it's [device] working"), and make explicit the pre-beginning of a turn (e.g. "You going to say something?") (Clarke et al., 2013; Clarke \& Wilkinson, 2008; Engelke \& Higginbotham, 2013). With these practices, the interlocutors' actions serve to maintain a sense of progressivity and a collaborative change in speakers (Clarke, 2016).

During aided conversations, the aided speakers first signal their intent to take a conversational turn. This pre-beginning to their speaking turn is typically achieved by gazing at their communication device, touching it, or otherwise physically orienting toward it, or by 
vocalizing and/or displaying some other physical action (such as hitting a table) (Clarke, 2005; Clarke \& Wilkinson, 2010; Sigurd Pilesjö, 2013). To ensure turn-transition success, the partner must notice the aided speaker's pre-beginning signals, then deal with the composition delay until the utterance is composed and issued. Studies on the pre-beginnings of aided conversations have indicated that noticing the unaided pre-beginnings can be a demanding task for partners (Clarke et al., 2013; Sigurd Pilesjö, 2013), especially when the aided speakers are children (Clarke \& Wilkinson, 2008). When an aided speaker operates the SGD by gaze or the aided turn is a first pair part of a sequence (Clarke et al., 2013), it is often more difficult for the partner to detect the pre-beginning, as they may not notice or correctly interpret the aided speaker's attempt to communicate (Clarke \& Wilkinson, 2010).

After the partner notices the pre-beginning of the aided speaker's utterance composition, they may wait in silence or produce co-occurring talk (Clarke et al., 2013; Higginbotham et al., 2016). These delays make the turn-transitions of aided conversations vulnerable to co-occurring talk as well as other parallel conversations and activities by the partner, which can impact the trajectory and outcome of the conversation (Clarke \& Wilkinson, 2010; Engelke \& Higginbotham, 2013; Noren, Svensson, \& Telford, 2013; Sundqvist, Plejert, \& Ronnberg, 2010). The shared access to the device display as well as the ongoing utterance composition may promote the partner's use of guessing, question asking, and commenting about the current composition (Clarke \& Wilkinson, 2010; Engelke \& Higginbotham, 2013; Noren, Svensson et al., 2013). In fact, the occurrence of symmetrical participation patterns that resemble those of spoken conversations is relatively uncommon and is dependent on whether the interlocutor is willing and/or able to make time for the aided speaker to complete their compositions 
(Batorowitz et al., 2014; Clarke et al., 2013; Engelke \& Higginbotham, 2013; Higginbotham et al., 2016; Noren, Svensson et al., 2013; Sundqvist et al., 2010).

To summarize the current literature, the research on aided turn-transitions in aidedconversations involving children has focused on identifying and evaluating the pre-beginning (Sigurd Pilesjö, 2013), the completing of an aided turn (Clarke et al., 2013) and the co-occurring talk of partners (Noren, Svensson et al., 2013) during turn-transition. However, few studies have focused on how young aided communicators and their partners contribute to the progress of turntransition by matching their actions.

Using conversation analytical methods (CA), this investigation examines how mothers who use natural speech and their sons who use SGDs address the normative demand to demonstrate conversation progress through their use of specific social interaction practices during turn-transitions. More precisely, this analysis focuses on how aided turn-transitions that do not respond to the adult turn are accomplished during interactions between the aided child communicators and their mothers. By observing and identifying how participants coordinate their actions in different parts of turn-transitions we attempt to highlight the factors that contribute to the progressivity of aided conversations. This study views young aided conversationalists as active participants who adopt different strategies to further their conversations. The results of this analysis could be utilized to further develop effective interaction strategies for communication partners and for AAC technologies that are intentionally designed to facilitate interactive communication (Higginbotham et al., 2016). 


\section{Method}

\section{Research Design}

This study used inductive video-based and microanalytic observations that were indicated by the transcriptions and the numerical data on the frequencies of participants' actions in turntransitions and durations of turn-transitions. The process of analysis progressed according to CA conventions and became more detailed through repeated video observations (Higginbotham \& Engelke, 2013; Mondada, 2014; Schegloff, 2007; Ten Haven, 2007). This study was approved by the appropriate ethics boards at the first authors' institutions.

\section{Participants}

Participants were recruited from a special school for children and youth with physical disabilities. After permission was granted by the school principal, the school speech-language therapists sent a recruitment letter to families who had a nonspeaking child who used an SGD as well as a communication book organized by communicative function in their everyday interaction. Informed consent was obtained for all participants. For participants under 18 years of age, both parents also signed an informed consent.

The aided communicators in this study were all male, ranging in ages from 7 to 18 years. Their pseudonyms were Jaakko, Paavo, Kalle, and Veeti (Table 1). Paavo communicated with over 100 manual signs, while Kalle used a few manual signs and gestures. All of the aided communicators produced aided multi-word utterances that were not always syntactically fully formed. All except Paavo used a wheelchair. The mothers of the aided communicators served as their communication partners for this study. The mothers were knowledgeable about their child's communication repertoire and AAC technology. In addition, to support their child's interaction with communication devices, they received training by speech-language therapists. 
Table 1

Summary of Participant Characteristics Using Aided Communication

\begin{tabular}{|c|c|c|c|c|c|c|c|}
\hline Name & Age & $\mathrm{GDV}_{\mathrm{a}}$ & $\mathrm{CFCS}_{\mathrm{b}}$ & Diagnosis & Speech & $\begin{array}{l}\text { Years of } \\
\text { Using } \\
\text { TAIKE }\end{array}$ & $\begin{array}{l}\text { Access } \\
\text { method }\end{array}$ \\
\hline Jaakko & 18 & 12 & III & $\begin{array}{l}\text { Aicardi- } \\
\text { Goutières } \\
\text { syndrome } \\
\end{array}$ & $\begin{array}{l}\text { Some words } \\
\text { produced with } \\
\text { vowels }\end{array}$ & 8 & Mouse \\
\hline Paavo & 11 & $5 c$ & IV & $\begin{array}{l}\text { Dyskinetic } \\
\text { cerebral palsy } \\
\text { (mild) }\end{array}$ & $\begin{array}{l}\text { Unintelligible } \\
\text { words }\end{array}$ & 2 & $\begin{array}{l}\text { Finger } \\
\text { pointing }\end{array}$ \\
\hline Kalle & 10 & 0 & II-III & $\begin{array}{l}\text { Arterial } \\
\text { ischemic stroke } \\
\text { of brainstem, } \\
\text { Tetra- and } \\
\text { bulbar paresis }\end{array}$ & Vocalizing & 4 & $\begin{array}{l}\text { Finger } \\
\text { pointing }\end{array}$ \\
\hline Veeti & 7 & $1.5 \mathrm{~d}$ & II & $\begin{array}{l}\text { Dyskinetic } \\
\text { cerebral palsy } \\
\text { (severe) }\end{array}$ & Vocalizing & 2 & Gaze \\
\hline
\end{tabular}

Note: Age in years during the period of video recordings. GDV = the gap between developmental and verbal age in years; CFCS = Communication Function Classification System with levels I-IV (Hidecker et al., 2011).

a Assessed by a psychologist but not measured for the present study. bAssessed by the speech and language therapist who was responsible for the therapy but not measured for the present study.

c The developmental age was 9 years old at the time of the assessment.

d The developmental age was 6 years and 7 months at the time of the assessment.

The conversations reported in this study featured participants who were all aided through their use of an SGD with the communication software Boardmaker with Speaking Dynamically Pro v.61® and a Finnish communication application, TAIKE v.2.2@ TAIKE is a dynamic communication system that includes hundreds of displays and thousands of symbols (Savolainen, 2010). The number of symbols and their organization varies across display pages (with a maximum of 65 symbols). These display pages are linked to the main menu, which is organized in terms of the common social actions in conversation, such as conversational starters, questions, 
and comments. TAIKE is also designed to support spoken conversation, including prestored social and topic-specific utterances. The aided communicator can use TAIKE either by selecting a prestored utterance or by composing an utterance symbol by symbol. Upon selection, each symbol appears in the message window. Utterances are issued by activating the message window, which in turn triggers the language generator module that produces syntactically fluent utterances in Finnish through speech-synthesis.

\section{Procedures}

This study focused on four conversations between the aided communicators and their mothers in their respective homes. The families were provided with video cameras (Handycam ${ }^{\circledR}$ HDR-CX24OE), instructions for framing the video shot, and strategies for solving common video-recording problems. The participants were informed that the focus of the study was on conversation and instructed to record a typical interaction situation involving the aided communicator with one of their parents during situations such as eating dinner or lying on the couch and conversing about their topics of choice. They were also free to use any of their communication aids and they organized the seating arrangements themselves before the recording began. The researchers were not present during the recording session, and a single video camera was set up by the parents so that the top part of the body of both participants and the communication device were visible. The duration of the conversation was not specified, varying from 27 to 47 min across dyads.

Data collection. First, the researchers transcribed the videos without strict attention to detail (e.g., prosodics, gestures, and timing) but preserved the basic sequential organization of the conversations. The conversations were then workshopped with other researchers who were familiar with CA and who viewed and discussed the videos with the authors. One important 
outcome of these interactions was the observation that the aided communicators in this study were actively engaged in conversing with their mothers and produced numerous first pair parts of sequences. These initial findings helped us focus our inspection on the intricacies of turntransitions before the aided communicator's first pair utterance parts.

The next step was for the first author was to compile the interaction sequences where the aided communicators produced a first pair part that consisted of at least one speech-synthesized word. Uncertain cases were discussed with the third author to ensure reliability. We excluded five utterances that were in a second pair part position but were constructed as first pair parts (such as asking a question). The resulting data used for this study were comprised of 99 aided first-pair parts, consisting of single and multi-word (i.e., pre-stored and composed) utterances, which varied extensively by topic.

Data analysis. The data were analyzed using CA where the main objective is to analyze conversationalists' practices in a particular interaction situation and to formulate rules by examining recurrent and exceptional cases (Ten Haven, 2007). The investigation centered on understanding the turn-transition structure that occurred before the first pair part of the utterance (Hayashi, 2013). We used a digital media transcription tool, InqScribe $4 \circledast$ to transcribe, insert timecodes, and adjust playback speeds that were critical for performing a fine-grained microanalysis of the conversations. Based on this analysis, we determined that the aided communicator's turn-transition before the first pair part of their utterance is more timeconsuming and complex than the turn-transitions of speaking partners.

Through the repeated analysis of the turn-transition corpora with a group of CA-oriented researchers, the analysis focused on the development of a model for aided turn-transition. The data were grouped according to the frequency of participants' actions in turn-transitions by 
distinguishing conventional cases from those that were exceptional. Uncertain cases were observed and discussed with the fifth co-author. Utilizing the timecodes, we calculated the durations of turn-transitions to establish the time frame of participant's actions. The excerpts of the conversations were prepared using both traditional CA methods and AAC transcription conventions (Appendix A), and their reliability was assured among the co-authors.

\section{Results}

During typical conversations between two speaking partners, the main focus of a turntransition is on how conversationalists coordinate their turns at a relevant place in the transition during their ongoing interaction (Sacks et al., 1974). In the conversations analyzed here, the turntransitions that led to issuing an aided utterance were larger projects, as the composition of an aided utterance took time.
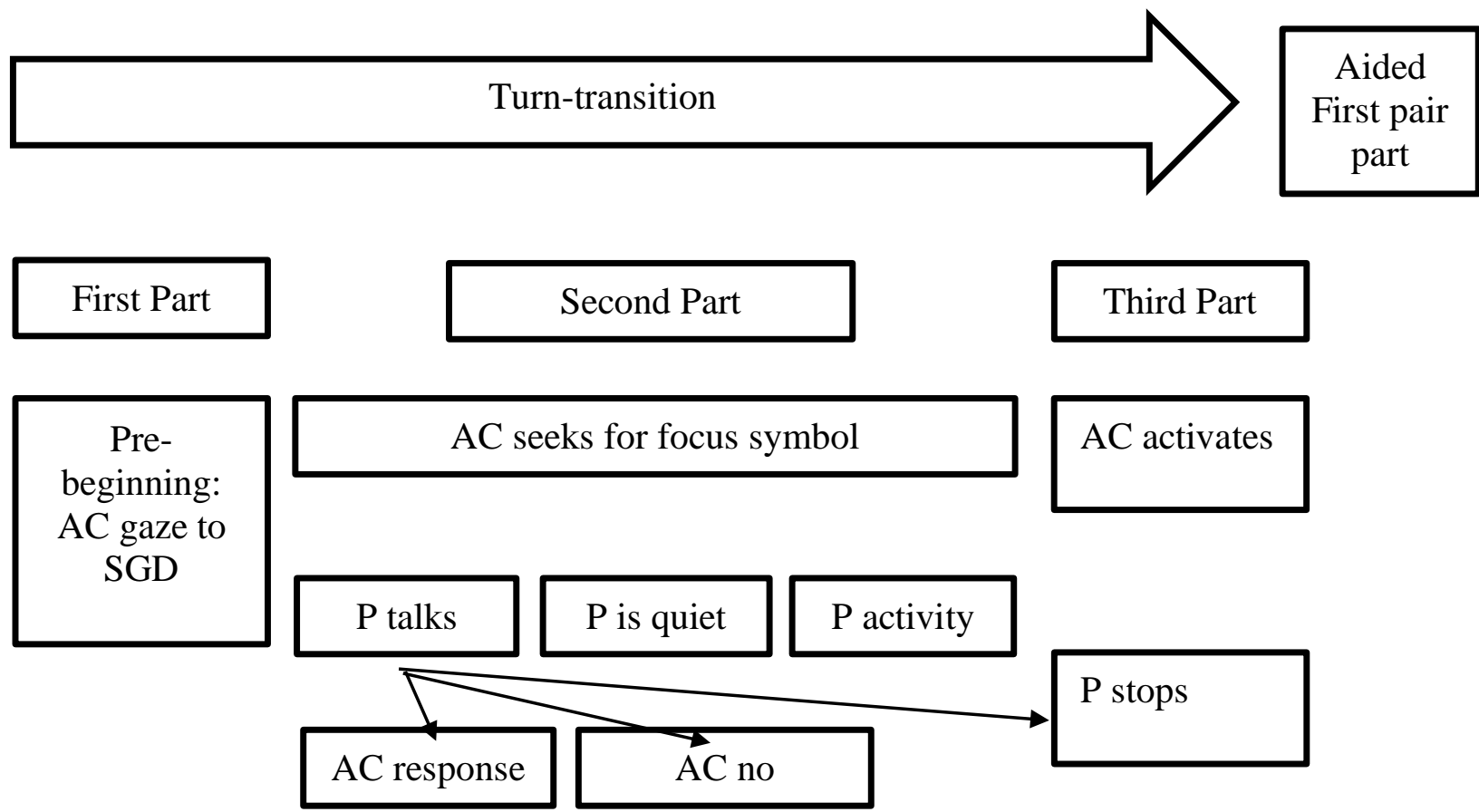

Figure 1. Aided communicator's (AC) and partner's (P) actions during the three-part turntransition before the aided first pair part. 
Figure 1 illustrates how the participants organized their turn-transitions before the aided first pair part in a three-part course. Initially, aided communicators began to prepare an aided first pair part by gazing at the SGD. Second, aided communicators continued preparations while their speaking partner either talked, remained quiet, and/or engaged in another activity. When the partner talked, the aided communicators either responded to that talk or ignored it. During the third part of the turn-transition, the aided communicators activated the cell that produced synthesized speech. The duration of the turn-transitions from the first pre-beginning to the first sound of the first synthesized word varied considerably within and between aided communicators, ranging between 1 and 81s (Table 2).

Table 2

Duration of Turn-transitions before Initiations of Aided Communicators

\begin{tabular}{lccccc}
\hline & & \multicolumn{4}{c}{ Duration in seconds } \\
\cline { 3 - 6 } \multicolumn{1}{c}{ Aided Communicator } & $\mathrm{N}$ & Median & IQR & Minimum & Maximum \\
\hline Jaakko & 20 & 8.5 & 13.75 & 1 & 81 \\
Kalle & 25 & 9 & 10 & 3 & 40 \\
Veeti & 10 & 15 & 14 & 2 & 41 \\
Paavo & 44 & 3 & 5.25 & 1 & 44 \\
\hline
\end{tabular}

Note: $\mathrm{IQR}=$ interquartile range.

The simplest turn-transition began with the aided communicator gazing at the SGD during a relevant point in the turn exchange while the partner remained quiet. The turntransitions were usually more complex, consisting of different actions performed simultaneously in the course of three-part turn-transitions. Next, let us turn to examine the participants' actions part by part in four excerpts and by consulting quantitative data. Each excerpt displays the threepart structure of a turn-transition. We present the first part of turn-transition are represented by excerpts 1 and 2, the second part by excerpts 1,2, 3 and the third part by excerpts $1,2,3$, and 4 .

\section{Part 1: Pre-beginning of Turn-transition}


During the beginning of a turn-transition, the aided communicator prepared to produce a word or an utterance through synthetic speech by shifting his gaze and, depending on the access method, moving his hand toward the SGD. After his gaze shift, the aided communicator might move his hand, click a mouse, or locate the target symbol with his eyes, depending upon his particular access method. Nonetheless, if the aided communicator returned his gaze to his partner and did not continue his pre-beginning activities, his gaze to an SGD was not regarded as a prebeginning.

During Part 1 of a turn-transition, the aided communicators' conventional pre-beginning was to shift their gaze to the SGD in a transition relevance place and to begin searching for the first symbol (55\% of turn-transitions, Table 3). Aided communicators also began to compose their utterances in overlap with their partner's unfinished speaking turns (31\%), as well as their own ongoing synthetic speech productions (8\%). Pre-beginnings of a turn-transition rarely cooccurred with the aided communicator's own turn, and did not appear in the excerpts.

Table 3

Frequency of the Aided Communicators' Gaze Shift Positions Relative to the SGD in the First Part of Turn-transitions

\begin{tabular}{lccccc}
\hline \multicolumn{1}{c}{ Position } & Jaakko & Paavo & Kalle & Veeti & $\begin{array}{c}\text { Total of } \\
\text { positions }\end{array}$ \\
\hline Partner's turn & 3 & 18 & 9 & 2 & 31 \\
Transition relevance place & 14 & 24 & 14 & 8 & 55 \\
Aided communicator's turn & 3 & 2 & 2 & 0 & 8 \\
$\quad$ Total of aided turn-transitions & 20 & 44 & 25 & 10 & 99 \\
\hline
\end{tabular}

Pre-beginning during a partner's turn. The first excerpt illustrates how Kalle anticipates his turn by beginning to compose his utterance during his mother's turn. At this point, Kalle and his mother are sitting side by side at the kitchen table. The mother is able to see when 
Kalle orients to his SGD, when his hand moves, and which cells he activates. The selected target cell cannot be seen in the video. The topic of their conversation is a school trip.

\section{Excerpt 1}

Conversation Between Kalle and Mother about a School Trip

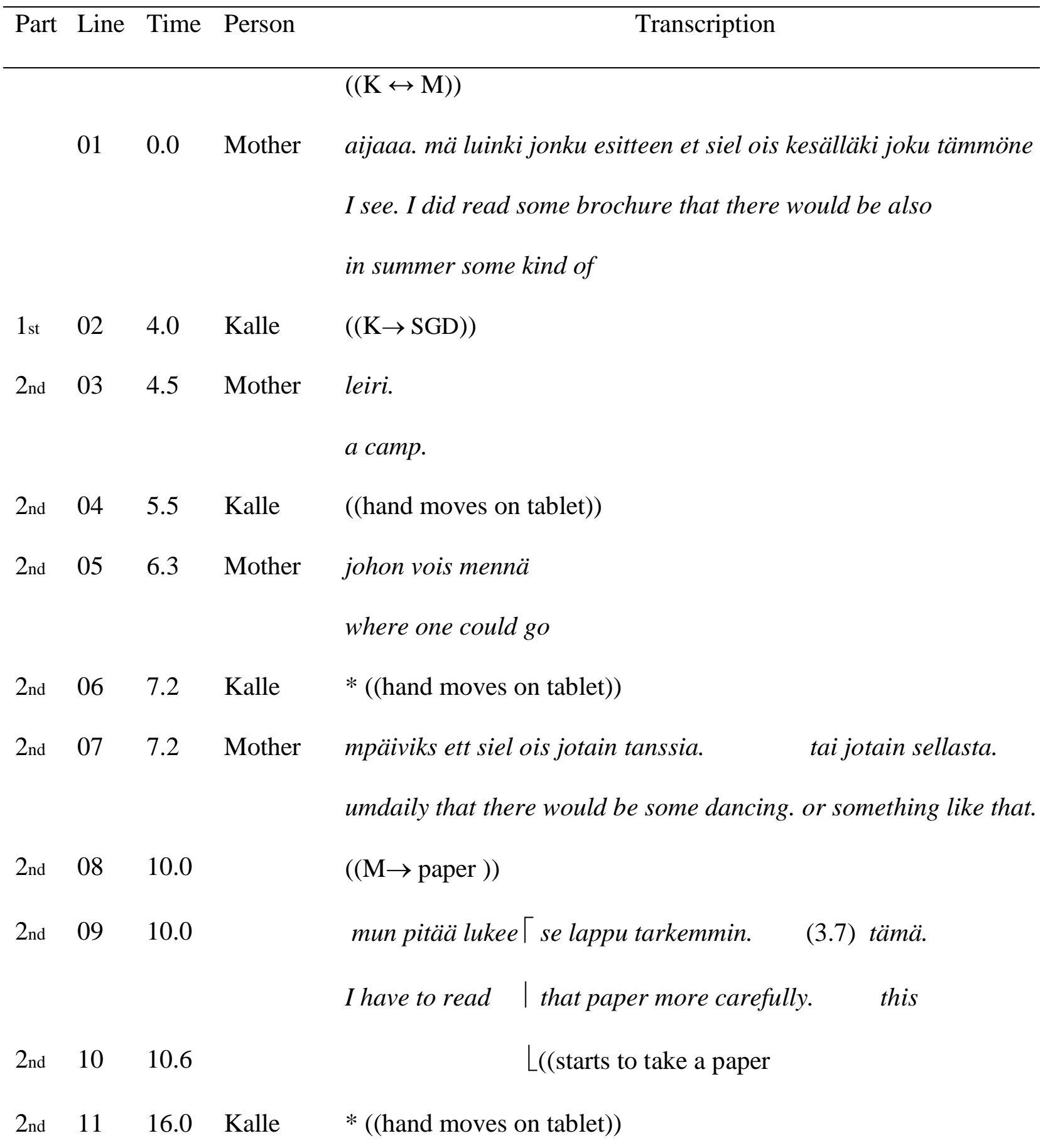




\begin{tabular}{|c|c|c|c|c|}
\hline $2 \mathrm{nd}$ & 12 & 16.7 & Mother & $\begin{array}{l}\text { värisevät } \\
\text { trembling }\end{array}$ \\
\hline 2 nd & 13 & 17.2 & Kalle & $*(($ hand moves on tablet $))$ \\
\hline $2 \mathrm{nd}$ & 14 & 17.2 & Mother & $\begin{array}{l}\text { varpaat. } \quad((\text { reads until line } 16) \\
\text { toes. }\end{array}$ \\
\hline 3rd & 15 & 18.1 & & $(2.3)$ \\
\hline$\rightarrow$ & 16 & 20.4 & Kalle & * “ensi” (24.0) "keskiviikko" (31.0) “me" (36.0) "mennä" \\
\hline & & & & "next” “Wednesday" \\
\hline & 17 & 45.3 & & ((writes “house of children” with mother; M $\rightarrow$ SGD)) \\
\hline$\rightarrow$ & 18 & 118 & & $\begin{array}{l}\text { * “ensi keskiviikkona me menemme lastentaloon” } \\
\text { ”next Wednesday we go to house of children” } \\
((\mathrm{K} \leftrightarrow \mathrm{M}))\end{array}$ \\
\hline & 19 & 123 & Mother & $\begin{array}{l}\text { oikeesti. se jatkuu vielä. wau. } \\
\text { really. it continues still. wow. }\end{array}$ \\
\hline
\end{tabular}

Prior to this excerpt, Kalle told his mother that he had visited the House of Children with his school's class, and they had danced there. The mother first produces a minimal response, "I see" (aijaa), and tells Kalle that she has read about the summer dance program that is offered there (Lines 1, 3, 5, 7, 8), then reads the camp brochure (Lines 12-15). After that, Kalle produces the aided first pair part, "Next Wednesday we go house of children" (Line 17), and the mother responds by stating "Really. It continues still. Wow!” (Line 18).

The first part of the turn-transition begins as Kalle turns his gaze to the SGD during the minimal pause when the mother is searching for the word (Line 2), and the transition continues 
as Kalle moves his hand and pointing finger to the SGD. Generally, the conversation participants in these data avoided long silences between turns, with no one talking or preparing to talk.

Pre-beginning during transition relevance places avoiding long gaps. The second excerpt illustrates how the participants act to avoid a long, silent gap during a transition relevant place. Excerpt 2 takes place between Jaakko and his mother during breakfast. They are sitting at the kitchen table at right angles to each other. Jaakko controls his device using a mouse, and the movements of the mouse are minimal. The mother is able to see Jaakko orient to his SGD and to hear his mouse clicks. Occasionally, the mother stretched across the table to view the SGD.

While it Jaakko's orientation to the SGD was visible in the video, the display was not in view.

Excerpt 2

Conversation Between Jaakko and Mother about Relatives

Part Line Time Person Transcription

$((\mathrm{M} \leftrightarrow \mathrm{J}))$

$01 \quad 0.0 \quad$ Mother niin on sulla on. maria ja tuula $\lceil$ ja kirsi ja tiina. $\rceil$ yes you have. maria and tuula |and kirsi and tiina. |

$02 \quad 2.6 \quad$ Jaakko

$L(($ nods $))$

$03 \quad 4.7 \quad$ Mother $\quad \mathrm{mm}$.

$04 \quad 5.4$

$05 \quad 7.7 \quad$ Mother ((nods) $)$

$06 \quad 8.8 \quad$ Jaakko $\quad(($ nods $))$

$07 \quad 9.5 \quad$ Mother ((nods))

$08 \quad 10.5$ 


\begin{tabular}{|c|c|c|c|c|}
\hline $1_{\text {st }}$ & 09 & 11.6 & Jaakko & $((\mathrm{J} \rightarrow \mathrm{SGD}))$ \\
\hline 2 nd & 10 & 11.6 & Mother & ${ }^{\circ} m^{\circ}$ \\
\hline 2 nd & 11 & 12.1 & & $(1.7)$ \\
\hline 2 nd & 12 & 13.8 & Mother & $((\mathrm{M} \rightarrow$ window $))$ \\
\hline $2 \mathrm{nd}$ & 13 & 13.8 & Jaakko & $*$ \\
\hline 2 nd & 14 & 15.6 & Mother & $\begin{array}{l}\text { ja } y k s \\
\text { and one } \\
((\mathrm{M} \leftrightarrow \mathrm{J}))\end{array}$ \\
\hline $2 \mathrm{nd}$ & 15 & 15.9 & Mother & $\begin{array}{l}\text { setä ja. kolme enoa } \\
\text { uncle and. three maternal uncles }\end{array}$ \\
\hline 2 nd & 16 & 17.9 & Jaakko & $(($ nods $))$ \\
\hline $2 \mathrm{nd}$ & 17 & 17.9 & Mother & ((burps)) \\
\hline 2 nd & 18 & 19.5 & & $\begin{array}{l}\text { mut kukas niitä nyt aattelee. } \quad\lceil((\text { smiles }))\rceil \\
\text { but who would ever think of them. }\end{array}$ \\
\hline $2 \mathrm{nd}$ & 19 & 20.1 & Jaakko & $\lfloor(($ smiles $))\rfloor$ \\
\hline 2 nd & 20 & 23.8 & Mother & $\begin{array}{l}€ \text { sää vaan puhut tädeistä aina. } € \\
€ \text { you only speak about aunts always. } €\end{array}$ \\
\hline $3 \mathrm{rd}$ & 21 & 23.8 & & $((\mathrm{M} \rightarrow$ other objects; takes a cup and starts to drink $))$ \\
\hline $3 \mathrm{rd}$ & 22 & 25.2 & & $(2.8)$ \\
\hline $3 \mathrm{rd}$ & 23 & 27.6 & Jaakko & $((\mathrm{J} \rightarrow \mathrm{SGD})) * * *$ \\
\hline$\rightarrow$ & 24 & 33.0 & & $\begin{array}{l}\text { “julia”(4.0)“olla”(18.0) “minä”(18.0) “paras”(11.0) } \\
\text { serkku”(3.0) ”juulia on minun paras serkku” }\end{array}$ \\
\hline & & & & "julia" “is" "my” "best" \\
\hline
\end{tabular}


“cousin” "julia is my best cousin”

2591.0 Mother onko. okei. te olitte pienenä aika paljon yhdessä. really. okay. when you were small you were a lot together

$26 \quad 91.0 \quad((\mathrm{M} \rightarrow \mathrm{J}))$

Notes: Maria, Tuula, Kirsi, Tiina and Juulia are women's names.

Before the excerpt, Jaakko stated that he has four aunts, with the mother producing a second pair part that displayed agreement, "Yes, you have." She then named his aunts, "Maria and Tuula and Kirsi and Tiina" (Line 1). After a prolonged turn-transition, (Lines 2-13), the mother carried on enumerating, "And one uncle and three maternal uncles" (Lines 14-15), which is syntactically bound to her utterance starting in Line 1 . The mother continues her turn saying "But who would ever think of them?" (Line 18), and then ends her turn with an explanation of the joke: "You only speak about aunts always." (Line 20). After agreeing, Jaakko utters the aided first pair part of "Julia is my best cousin." (Line 24), and the mother comments "Really. Okay. When you were small you were together a lot" (Line 26).

The second excerpt serves as evidence for how the participants try to avoid long silences between turns. After Jaakko has confirmed his mother's naming of his aunts (Lines 1-2), the mother replies with the neutral response particle "Mm" then relinquishes the floor to Jaakko by gazing at him (Line 3). However, Jaakko does not immediately take the turn (Line 4). After a 2.3s lapse, his mother fills the space by nodding and protracts the end of the sequence. Jaakko responds, in turn, by nodding, and the mother confirms by nodding again. By co-producing their previous behaviors (i.e., nodding) (Lines 5-7), both participants can be seen to treat the prior stretch of interaction as a conspicuous delay in turn-taking (Hoey, 2015). As a pre-beginning, Jaakko turns his gaze from the mother to the SGD to compose his next utterance, while his 
mother voices $M$ under her breath as Jaakko turns toward the device (Lines 9-10). The turntransition begins at this point and continues through the second and third parts, which are analyzed in the following sections.

To summarize, Excerpts 1 and 2 exemplify how the aided communicator initiates his own turn at a turn-transition point or during his mother's turn, and the strategies that the participants use to avoid long silences between turns.

\section{Part 2: The Middle of Turn-transition}

The second part of the turn-transition was characterized by the aided communicator continuing to compose an utterance. During this time, their partners talked, remained quiet, and/or engaged in another activity. The aided communicators either responded to their mothers' action in the middle of their composing process or ignored them.

The mothers' talking in the middle of turn-transitions during utterance composition was a typical practice that occurred across $82 \%$ of the middle turn-transition events (Table 4 ). These events represented a continuation of the previous sequence in $68 \%(55 / 81)$ of the cases (see Excerpts $1 \& 2$ ). Typically, the mother would relinquish her turn and remain silent during the rest of the aided communicator's process of composition. In $32 \%$ of the cases (26/81), the mother produced a first pair part of a sequence (an initiation) during the turn-transition. This occurred most frequently when the aided communicator began to compose an utterance at the same time as his mother began talking. The mother's utterances were often associated with (a) emergent events, such as eating, reading (Excerpt 1: Lines 12-15), use of the SGD; (b) someone else entering the room; or (c) speaking to herself. This type of talk was particularly common to the mothers of Kalle and Veeti. In the data, turn-transitions also occurred when the mothers remained silent (18\%), but these do not occur in the excerpts. 
Table 4

Frequency of the Mothers' Actions in the Second Part of Turn-transitions

\begin{tabular}{lccccc}
\hline \multicolumn{1}{c}{ Mother's action } & JM & PM & KM & VM & $\begin{array}{c}\text { Total of } \\
\text { actions }\end{array}$ \\
\hline Continues current sequence & 9 & 31 & 12 & 3 & 55 \\
Produces an FPPa & 3 & 6 & 11 & 6 & 26 \\
Is quiet & 8 & 7 & 2 & 1 & 18 \\
$\quad$ Total of aided turn-transitions & 20 & 44 & 25 & 10 & 99 \\
\hline
\end{tabular}

Note: FPP = first pair part of sequence; JM = Jaakko's mother, the letter before M refers to the boy's name. a Mother produces either a first pair part or instead continues current sequence and after that, produces a first pair part.

The mothers' non-spoken actions rarely demanded the aided communicators' reply, with aided communicators responding to only $19 \%$ of their mother's actions (Table 5). The majority of the non-spoken responses used to confirm or display agreement with the previous utterance consisted of nodding, shaking, smiling, or uttering a sound or short words such as "yes" or "no" (see Excerpt 2: Lines 16 and 19).

Table 5

Frequency of the Aided Communicators' Reactions to the Mothers' Actions in the Second Part of Turn-transitions

\begin{tabular}{lccccc}
\hline Aided Communicator's Reaction & Jaakko & Paavo & Kalle & Veeti & $\begin{array}{c}\text { Total of } \\
\text { Reactions }\end{array}$ \\
\hline Response & 5 & 8 & 6 & 0 a & 19 \\
No response & 15 & 36 & 19 & 10 & 80 \\
$\quad$ Total of aided turn-transitions & 20 & 44 & 25 & 10 & 99 \\
\hline
\end{tabular}

Note: a Veeti typically began his production process by shifting his gaze to the SGD and vocalizing. Some vocalizations could have also been responses to his mother's actions, but to prevent ambiguity, they are not counted as responses.

Mothers' talk and aided communicators' reactions. The first and second excerpts, which were introduced earlier, illustrate how the mothers talk and engage in parallel activities during the middle part of a turn-transition. In the first excerpt, Kalle's mother continues her 
previous utterance even though she sees that Kalle is composing his own utterance (Lines 3, 5, 7, 8) and she then occupies herself during the delay by reading a brochure (Lines 12-15). In this excerpt, Kalle does not react to his mother's talk but instead concentrates on his composition process. During the second excerpt, Jaakko discontinues his message composition to respond to his mother's talk by not using a SGD. After Jaakko's gaze shift to the SGD, the mother remains silent for 4s (Lines 10-12) and begins talking again, producing an utterance that is syntactically connected to her previous utterance And one uncle and three maternal uncles (Lines 14-15). During the mothers' talk, Jaakko interrupts his composition, both participants look at each other, and Jaakko acknowledges her talk by nodding (Line 16). The mother continues her turn by stating But who would ever think of them (Line 18), which invites Jaakko to participate in her joke by looking and smiling at Jaakko, who in turn returns her smile (Line 19). When the mother ends her turn with an explanation of the joke: You only speak about aunts always (Line 20), she breaks eye contact and orients toward her coffee (Line 21). Jaakko does not respond further to her explanation, but looks at his mother drinking (Line 22), then orientates back to the SGD to finish his composition (Lines 23-24).

Exceptional case of aided response. The third excerpt illustrates the exceptional case of an aided response, which confirms that unaided responses are preferable to aided responses in turn-transitions. In the excerpt, Veeti replies to his mother's question by aided means, but he does not interrupt the composition process as he responds later in the conversation. Veeti and his mother are sitting side by side at the kitchen table. Veeti controls his device with his gaze. The mother sees when Veeti orients to his SGD, moving his gaze on the display and pointing at the target cell. The position of the selected cell could not be transcribed because only the directions 
of Veeti's head are visible in the video. The social action of Veeti's aided first pair part is to request help.

Excerpt 3

Conversation Between Veeti and Mother. Veeti Asks for Help.

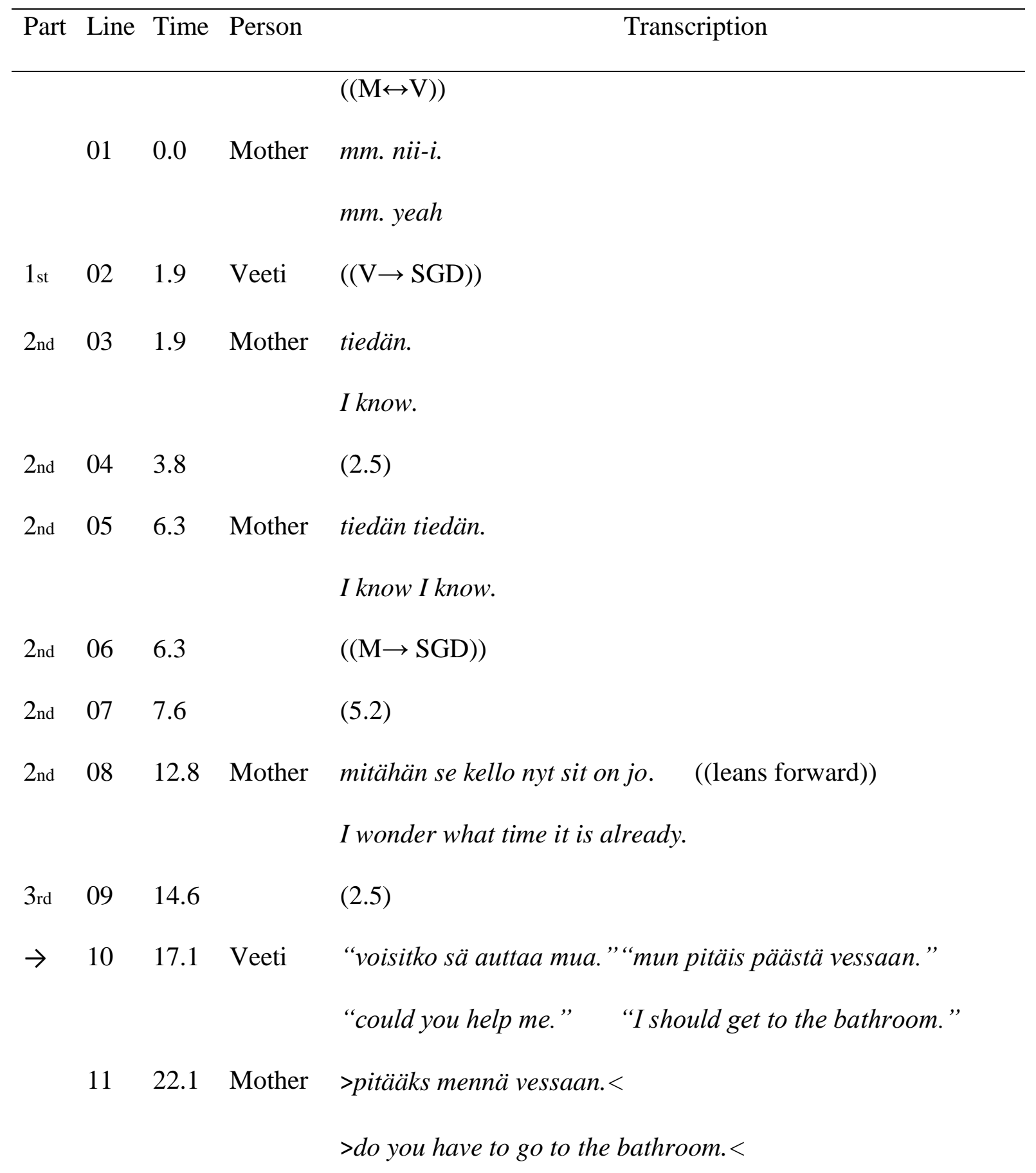


$12 \quad 22.1 \quad((\mathrm{M} \rightarrow \mathrm{V}))$

((takes napkin under Veeti's jaw and puts magazin to table))

$13 \quad 23.8 \quad((\mathrm{M} \rightarrow$ glance $\mathrm{SGD} \rightarrow$ other objects $))$

$1424.8 \quad$ okei. tottakai. kipin kapin

okay. of course. hurry up

$15 \quad 26.0 \quad$ ((stands up; gaze is not seen $))$

1628.4 Veeti “kello on. kolme kolmekymmentä kolme.” ((smiles))

"the time is. three thirty three."

$17 \quad 28.4 \quad((\mathrm{~V} \rightarrow \mathrm{M}))$

$18 \quad 32.0$ Mother joo hyvä. on viel aikaa.

all right good. there is still time.

Prior to the excerpt, Veeti stated that he liked the idea of his school excursion to a zoo in May, and his mother continues the topic, confirming Veeti's opinion by using two different response particles. The first is the neutral $\mathrm{Mm}$, and the second is Yeah (niin) (Line 1), which is used in Finnish conversations when a speaker acknowledges the feelings of co-participants and accepts them (VISK $\S 798$ ). In this position, a turn-transition is relevant to start, and Veeti shifts his gaze to the SGD (Line 2) and begins to issue his prestored utterance, requesting help "Could you help me" "I should get to the bathroom." (Line 10). The mother answers the request, repeating part of Veeti's utterance within a Do question frame, Do you have to go to the bathroom, while at the same time preparing for the toilet excursion (Lines 11-12). The mother continues answering Veeti's request by saying Okay of course, then gets up and says Hurry up (Line 14). 
In the middle of the turn-transition (Lines 3-8), Veeti's mother continues speaking in the same manner as the other mothers in the first and the second excerpts. After Veeti's gaze shift to the SGD, his mother continues to underline the meaning of the previous sequence by saying $I$ know (Line 3). She recognizes Veeti's changed orientation, and after $2.5 \mathrm{~s}$ of silence, she fills the empty space of turn-transition, repeating twice, I know (Line 5) while shifting her gaze to the SGD (Line 6). His mother is then quiet for another 5.2s (Line 7), but then she leans forward slightly, probably to better see the time on the SGD display, and states I wonder what time it is already? (Line 8). The mother uses a question word What in Finnish, mitä-, with the clitic particle - hän, which makes a question rhetorical (i.e., an answer is not needed) (VISK $§ 1705$ ). Veeti continues his current composition but answers the current question later (in Line 16). After Veeti's request for help, he does not shift his gaze to his partner, which is a common practice at the end of an aided utterance (Clarke et al., 2013), but continues looking at his device while composing an answer to is mother's last question. As the mother begins to rush Veeti to the bathroom, she gives Veeti time to produce his next utterance, standing next to Veeti's wheelchair (Line 15). Veeti produces an aided response to his mother's rhetorical question, "The time is. Three thirty three" (Line 16) and smiles. The mother produces a response, All right good. There is still time (Line 18), which is probably related to their visit to Veeti's grandmother and grandfather shortly after this conversation.

To summarize, the previous excerpts demonstrate that the mothers' talk during the turn-transition did not obligate the aided communicators to produce a reply, and the possible responses are typically unaided (such as a nod and/or a smile), ensuring the flow of conversations. Next, we present examples of mothers discontinuing their talk before the aided 
communicator activates the speech output in the third part of the turn-transition, but the aided communicators may speak in overlap their mother's speech.

\section{Part 3: The End of turn-transitions}

Turn-transitions ended when the aided communicator issued the first speech-synthesized sound word or prestored utterance, and the speaking turn was subsequently shifted to the aided communicator. The durations of the turn-transitions varied (Table 2). In the first excerpt, total duration of the turn-transition was $15.6 \mathrm{~s}$, whereas in the second excerpt it was $21.4 \mathrm{~s}$, and in the third excerpt, $15.2 \mathrm{~s}$.

The third part of the turn-transition was usually preceded by silence (68\%) (Table 6), as the speaking partner stopped talking either at the start of the aided communicator's message composition or during it (Excerpt 1: Line 15; Excerpt 2: Lines 21-23; Excerpt 3: Line 9). In typical everyday conversations, a common practice is to avoid long gaps and overlaps, so that the turns latch smoothly from one to the next (Sacks et al., 1974). During aided conversations, however, both latched transitions (14\%) and overlaps (17\%) occurred infrequently. When overlaps did occur, it was usually the aided communicators who spoke over their mother's speech. The number of silent gaps preceding the third part of the turn-transition served as evidence that the mothers recognized the aided communicators' composition and intentions to take a speaking turn in the near future. 
Table 6

Frequency of the Participants' Timing Practices of Their Turns in the Third Part of Turntransitions

\begin{tabular}{lccccc}
\hline \multicolumn{1}{c}{ Timing Practice } & J \& JM & P\&PM & K\&KM & V\&VM & $\begin{array}{c}\text { Total of } \\
\text { practices }\end{array}$ \\
\hline Gap & 16 & 23 & 22 & 7 & 68 \\
Minimal gapa or Latch & 2 & 9 & 1 & 2 & 14 \\
Overlap & 2 & 12 & 2 & 1 & 17 \\
$\quad$ Total of aided turn-transitions & 20 & 44 & 25 & 10 & 99 \\
\hline
\end{tabular}

Note: $\mathrm{J}=$ Jaakko; JM = Jaakko's mother

a Minimal gap was less than one second.

Overlapping at the end of turn-transition. The fourth excerpt illustrates how Kalle times the cell activation of the focus symbol to occur in the middle of his mother's talk, causing an overlap at the end of the turn-transition.

Excerpt 4

Conversation Between Kalle and Mother. Kalle Asks about Relative's Funeral.

Part Line Time Person $\quad$ Transcription

$$
((\mathrm{K} \leftrightarrow \mathrm{M}))
$$

1st $\quad 01 \quad 0.0 \quad$ Kalle $\quad((\mathrm{K} \rightarrow \mathrm{SGD}$; starts to move hand $))$

2nd $\quad 02 \quad 1.0 \quad$ Mother $\quad((M \rightarrow S G D))$

2nd $\quad 03 \quad 1.3 \quad$ Kalle $\quad *$

2nd ] $04 \quad 1.3$ Mother eli hyvä viikonloppu tiedossa.

so a good weekend coming

2nd $\quad 05 \quad 1.3 \quad((\mathrm{M} \rightarrow \mathrm{K}))$

2nd $\quad 06 \quad 2.5 \quad$ Kalle $\quad *$ 
2nd $07 \quad 3.0$ Mother pitsaperjantai Koti 「pizzastaja sitte Noran a pizzafriday from Home I pizza and then with Nora
2nd $\quad 08 \quad 4.0$
$\llcorner((\mathrm{M} \rightarrow \mathrm{SGD}))$
2nd $\quad 09 \quad 6.3 \quad$ Kalle $\quad *$
3rd $10 \quad 6.3$ Mother kanssa lau $\lceil$ antai ja sunnuntai $\rceil$ (glos. with) Sa turday and Sunday |
3rd $11 \quad 6.7 \quad$ Kalle
| "hautajaiset" |
$\rightarrow$
L "funeral" $\rfloor(($ hand moves $))$

128.7 Mother kene hautajaiset

whose funeral

$\begin{array}{lll}13 & 8.7 \quad((\mathrm{M} \rightarrow \mathrm{K}))\end{array}$

$\rightarrow \quad 14 \quad 22.3$ Kalle $* * * *$ "Tampere"

$1524.0 \quad((\mathrm{~K} \rightarrow \mathrm{M}))$

1624.0 Mother ai milloin me mennään niihi Liisan hautajaisiin sinne

Tampereelle

oh when we will go to the Lisa's funeral to Tampere

$17 \quad 27.0 \quad$ Kalle $\quad(($ nods $))$

1828.0 Mother se on silloin kun meillä alkaa kesäloma

it is then when we start a summer holiday

Notes: Kotipizza is the name of the pizza company. Tampere is the city of Finland.

Before this excerpt, Kalle and his mother discussed plans for doing something in the future over the weekend. Kalle then begins to compose his next utterance by gazing at the SGD 
display and moving his hand in a transition relevance place (Line 1). The mother first gives time to Kalle (Lines 1-2), but after 1.3s silence, she starts to produce a summary of their previous conversation So a good weekend coming... (Line 4, 7, 10), similar to previous excerpts. Kalle produces the first word of his aided initiation "Funeral" (Line 11) and continues the composition, maintaining his gaze at the SGD and moving his hand, but the mother interrupts asking Whose funeral (Line 12), and Kalle says "Tampere" (a city in Finland), and gazes toward his mother (Lines 14-15). After confirming the meaning of his utterance (Lines 16-17), the mother interprets it as a question about the time of the funeral and responds to the question in Line 18.

In this excerpt, the turn-transition that occurs before the word 'funeral' is quick, with a duration of $6.7 \mathrm{~s}$. During that time, the mother talks, repeating the content of the previous sequence. While she is talking, Kalle continues to compose her utterance (see the cell activations in Lines 3, 6 and 9), and consequently avoids responding to his mother's utterance. In this excerpt, Kalle does not wait for his mother's talk to end in the third part of the turn-transition, but he utters the word 'funeral' in the middle of the mother's utterance production (Lines 10-11). This overlap occurs where the meaning of the mother's previous talk is already clear. In short, the turn-transitions ended typically in silence on the part of the speaking partner, and possible overlappings were the aided communicators' action.

\section{Discussion}

The current study revealed a three-part turn-transition sequence that preceded the aided communicators' production of an utterance. Examining interactions in this manner helped us to reveal the conversationalists' cooperative actions during turn-transitions and to demonstrate how participants orientate their attention to further conversations. This section will address several 
issues that are related to the results, such as progressivity, the quality of conversations, clinical implications, limitations, and future directions for research.

\section{Progressivity}

Both participants in the data orientated to the progress of conversation, which was evident in their multimodal and interlocked actions in the three-part turn-transitions.

The first part of turn-transitions. The aided communicators in this study initiated the first part of a turn-transition by shifting their gaze to the SGD, which differs from spoken conversations that involve the speaker's gaze being directed to the recipient's face (Clarke, 2005; Schegloff, 1996; Sigurd Pilesjö, 2013). The aided communicators performed this pre-beginning either during a gap, in the middle of their mother's turn, or during their own utterance (via their SGD) (see Hayashi, 2013). Starting a new aided turn during the preceding spoken or aided utterance may have helped the aided communicator to take his turn or extend it and speed up the conversation.

It was interesting to note that the speaking partners did not interpret the aided prebeginnings as a signal to discontinue their turn, but instead continued their current sequence. This indicated that the aided communicator's actions were regarded as anticipatory signs of an aided turn under composition, rather than as overlaps are treated in spoken conversations (see Sacks et al., 1974). Directing one's gaze towards a device provides opportunities for speaking partners to be on alert for an upcoming aided turn, but there was no compelling reason to react to the pre-beginning.

The second part of turn-transitions. The most common option was to continue speaking, but in some phase of the second part of transitions, the mothers were quiet. At the latest, when the aided communicators uttered their first word with synthetic speech, the speaking 
partners had generally ceased talking and waited in silence, often engaged in another activity. Unlike a conspicuous lapse, the silences were treated similarly to spoken conversations in which participants engaged in intervening activities (Clarke \& Wilkinson, 2010; Mondada, 2014). Each of these different speaking partner activities allowed time for the aided communicator to compose their utterance, reinforcing the symmetry of participation, particularly if the speaking partner was silent (Noren, Svensson et al., 2013).

Despite any co-occurring talk involving the speaking partner, both participants demonstrated an orientation to the overall progress of the conversation in all the analyzed conversations. When a mother issued a first pair part during transitions, it did not obligate the aided communicator to respond immediately and was generally related to a parallel activity or speaking to themselves. The aided turn-transition process appeared to provide a context for different activities to occur. For example, co-occurring talk was treated as a relevant, allowable contribution, much the same as it does when lapses occur in spoken conversations (Hoey, 2015).

During turn-transitions, the aided communicators were also orientated to conversational progress, and they rarely responded to co-occurring talk. When they did respond, they did so through nods or other behavior that could be issued without disrupting their own ongoing composition. The speaking partners did not pursue responses, and the aided communicators appeared to have the right to prefer progress in the same way as in spoken conversations, where participants have a right to complete their in-progress activity (Sacks et al., 1974).

The third part of turn-transitions. Delays between turns were often sufficiently long so that the aided communicators rarely latched their first activation to the speaking partner's talk. The maximum duration of turn-transitions varied from 40-80 seconds, which reflects the slowness of aided conversations as compared to spoken conversations and considering the access 
method of an SGD. Our data contained only a few instances of participants matching their turns successfully by minimal gaps and overlaps, which are typical in spoken conversations (Sacks et al., 1974). In addition, some longer lasting overlaps occurred and during these, the aided communicator activated the focus cell in the middle of the speaking partner's talk, perhaps demonstrating a right to take a turn.

\section{Quality of the Conversations}

During the conversations of this study, the participants were present for each other, and they did not have any other duties or timetable. The aided communicators did not encounter challenges when entering ongoing conversations, and the mothers had an opportunity to concentrate on their sons without significant diversions. Contrary to previous research on asymmetric aided conversations with peers (Clarke \& Wilkinson, 2008; 2010; Higginbotham \& Wilkins, 1999; Higginbotham et al., 2016; Sundqvist et al., 2010) or with a teacher or an assistant (Noren, Svensson et al., 2013; Sundqvist et al., 2010), the aided communicators took initiative, and the mothers gave space for an aided turn-transition.

Several reasons could account for the fluency of these conversations. First, all the aided communicators in this study were educated, received extensive rehabilitation training and were able to produce multi-word aided utterances that were supported by the TAIKE communication application. It is noteworthy that the conversations progressed fluently, even though the aided communicators did not achieve the highest level (Level 1) for their everyday communication performance according to CFCS, and only Kalle's verbal age was equivalent to his developmental age according to psychologist's assesment. Second, the speaking partners were the mothers of the aided communicators, which means they shared an immense amount of common knowledge and experience communicating together. Furthermore, the mothers were 
taught a variety of interaction strategies to successfully scaffold their children's utterances. Finally, the recording context provided the interactants the opportunity to interact for a prolonged period of time without having to deal with extenuating circumstances. For these reasons, the observed conversations may represent a high quality of interaction achieved by participants with the orientation, skills, and time to carry out their interactions unimpeded by external circumstances.

\section{Clinical Implications}

The results of the present study contribute to the notion that AAC is fundamentally an interactive enterprise, and that both participants' actions are necessary to achieve conversational progress. Identification of multiple parts to achieve a turn-transition needs to be recognized as a critical part of utterance production and should further orient clinicians consider the following implications from this study:

1. Even though aided conversations are by nature slow, a speaking partner's practice of allowing time for a production processes reinforces the fluency of aided conversations.

2. Aided communicators can begin to compose their utterances during their partner's turn, as rather than interrupting conversation, this signals their upcoming turn. Conversely, speaking partners need to be able to recognize that their aided partners are beginning their utterance composition by shifting their attention to their device.

3. Partners do not have to discontinue their turn when they notice the pre-beginning, but they may want to refrain from obligating their partners to respond while they are composing their utterance. 
As part of the practical implications of this study, it was apparent that while the use of the AAC device facilitated linguistic production, it was not designed to promote smooth communication interactions. One specific finding was the AAC device was not designed to handle intervening questions posed by the speaking partners during message composition. This can be particularly problematic if the aided communicator are unable to answer by using their body-based communication modalities. Although multiple message windows and side-talk have been proposed and developed for some devices, these features are infrequently implemented or designed to function within actual conversation practice. Microanalytic studies such as the present study provide an optimal research context to analyze how devices are actually employed during conversation as well as the consequences of inadequate device design (Higginbotham et al., 2016; Pullin, Treviranus, Patel, \& Higginbotham, 2017)

\section{Limitations and Future Directions}

This study has some limitations that need to be addressed in future research. First, only a single camera was used in the investigation and this precluded recording the device display during conversation. Future studies need to include additional cameras to capture other important aspects of the interaction. Second, the study focused on the analysis of the first pair part of a sequence initiated by the aided communicator. To establish a fuller picture of aided communicative interaction, further research is needed to explore whether the interaction sequences reported in this study are a common feature among other aided communicators across different interaction situations and AAC systems, including low-tech aids. It would also be important to extend this research to examine turn-transitions across other interaction sequences, such as responses to questions and other directives. 
This study supports the line of reasoning that participants in aided conversations use many of the same means as speaking conversants to advance the temporal and structural flow of interaction, even though they may differ substantially in their pace, rhythm, and modality (Noren, Samuelsson et al., 2013; Sigurd Pilesjö, 2013). This is an important finding for several reasons. First, it reinforces the idea that participants in aided interaction draw on the same social knowledge and conventions employed by participants in society as a whole, and not conventions that are idiosyncratic to AAC. Even though research on CA is replete with interesting parallels to aided interaction, this is rarely recognized in the general AAC research literature. Second, the similarities between aided and spoken conversation should encourage researchers to adopt the same concepts and tools of CA, such as turn, sequence, and microanalysis. Researchers would thus benefit from exploring the half-century of research conducted in the area of CA with respect to understanding the intricacies of conversation, the ways that aided conversation relates to other genres of talk-in-interaction, and the research methodologies used to record and analyze conversation. Finally, the temporally expanded turn-transitions, characteristic of aided interactions, can provide the researcher a fine-grained perspective on transition practices not easily analyzed in the faster-paced interactions, particularly in terms of pace, rhythm, modality, and the influence of AAC technology. Such insights can extend the traditional speech-based models of turn-transition (see Sacks et al., 1974), and may offer new insights into the plans and actions that occur during turn-transition (see Levinson, 2013).

\section{Conclusion}

This paper describes successful aided conversations, which have rarely been a focus in previous studies. The analysis of the aided turn-transitions conducted here has extended our understanding of the structure of aided turn-transitions in conversations that use an SGD as well 
as of participants' actions in the progress of a conversation. The identification of the aided turntransition before aided initiations helps to identify participants' practices that contribute to conversations. This information can be utilized when professionals guide aided communicators and their communication partners in their interaction. 


\section{End Notes}

1 The Boardmaker® with the Speaking Dynamically Pro is a product of the Tobii Dynavox of Danderyd. www.tobiidynavox.com/software

2 TAIKE is a product of the Communication and Technology Center Tikoteekki of Helsinki. www.papunet.net/tikoteekki/materiaalit/taike 3 Handycam HDR-CX24OE is a product of the SONY. www.sony.fi/electronics

4 InqScribe is a product of the Inquirium, LCC. www.inqscribe.com 


\section{References}

Batorowicz, B., Campbell, F., von Tetzchner, S., King, G., \& Missiuna, C. (2014). Social participation of school-aged children who use communication aids: The views of children and parents. Augmentative and Alternative Communication, 30, 237-251.

doi:10.3109/07434618.2014.940464

Binger, C., \& Light, J. (2008). The morphology and syntax of individuals who use AAC:

Research review and implications for effective practice. Augmentative and Alternative Communication, 24, 123-138. doi:10.1080/07434610701830587

Clarke, M. (2016). Co-construction, asymmetry and multimodality in children's conversations. In M. M. Smith, \& J. Murray (Eds.), The silent partner? Language, interaction and aided communication (pp. 177-198). Guildford: J \& R Press.

Clarke, M. T. (2005). Conversational interaction between children using communication aids and their peers (Doctoral dissertation). http://discovery.ucl.ac.uk/id/eprint/1445394

Clarke, M., Bloch, S., \& Wilkinson, R. (2013). Speaker transfer in children's peer conversation: Completing communication-aid-mediated contributions. Augmentative and Alternative Communication, 29, 37-53. doi:10.3109/07434618.2013.767490

Clarke, M., \& Wilkinson, R. (2008). Interaction between children with cerebral palsy and their peers 2: Understanding initiated VOCA-mediated turns. Augmentative and Alternative Communication, 24, 336-348. doi:10.1080/07434610701390400

Clarke, M., \& Wilkinson, R. (2010). Communication aid use in children's conversation: Time, timing and speaker transfer. In H. Gardner, \& F. Michael (Eds.), Analysing interaction in childhood: Insights from conversation analysis (pp. 249-266). Singapore: Wiley. 
Enfield, N. J. (2013). Relationship thinking: agency, enchrony, and human sociality. Oxford: University Press.

Enfield, N. J. (2017). How we talk: The inner workings of conversation. New York: Basic Books.

Engelke, C., \& Higginbotham, D. (2013). Looking to speak: On the temporality of misalignment in interaction involving an augmented communicator using eye-gaze technology. Journal of Interactional Research in Communication Disorders, 4, 95-122.

Hayashi, M. (2013). Turn allocation and turn sharing. In J. Sidnell, \& T. Stivers (Eds.), The handbook of conversation analysis (pp. 167-190). Chichester: Wiley-Blackwell.

Hidecker, M. J. C., Paneth, N., Rosenbaum, P. L., Kent, R. D., Lillie, J., Eulenberg, J. B., Chester, K., Johnson, B., Michalsen, L., Evatt, M., \& Taylor, K. (2011). Developing and validating the communication function classification system (CFCS) for individuals with cerebral palsy. Developmental Medicine and Child Neurology, 53, 704-710.

Higginbotham, D. J. (1989). The interplay of communication device output mode and interaction style between nonspeaking persons and their speaking partners. Journal of Speech and Hearing Disorders, 54, 320-333. doi:10.1044/jshd.5403.320

Higginbotham, D. J., \& Wilkins, D. P. (1999). Slipping through the timestream: Social issues of time and timing in augmented interactions. In D. Kovarsky, M. Maxwell, \& J. Duchan (Eds.), Constructing (in) competence: Disabling evaluations in clinical and social interaction (pp. 49-82). London: Psychology Press.

Higginbotham, D. J., \& Engelke, C. R. (2013). A primer for doing talk-in-interaction research in augmentative and alternative communication. Augmentative and Alternative Communication, 29, 3-19. 
Higginbotham, J., Fulcher, K., \& J. Seale (2016). Time and timing in interactions involving individuals with ALS, their unimpaired partners and their speech generating devices. In M. Smith, \& J. Murray (Eds.), The silent partner? Language, interaction and aided communication (pp.199-228). Guildford: J\&R Press.

Hoey, E. M. (2015). Lapses: How people arrive at, and deal with, discontinuities in talk. Research on Language and Social Interaction, 48, 430-453. doi:10.1080/08351813.2015.1090116

Jefferson, G. (2004). Glossary of transcript symbols with an introduction. In G. H. Lerner (Ed.), Conversation analysis: Studies from the first generation (pp. 13-31). Amsterdam: John Benjamins.

Levinson, S. C. (2013). Action formation and ascription. In J. Sidnell \& T. Stivers (Eds.), The handbook of conversation analysis (pp. 103-130). Chichester: Wiley-Blackwell.

Mondada, L. (2014). The temporal orders of multiactivity. In P. Haddington, T. Keisanen, L. Mondada, \& M. Nevile (Eds.), Multiactivity in social interaction: Beyond multitasking (pp. 33-75). Amsterdam: John Benjamins Publishing Company.

Noren, N., Samuelsson, C., \& Plejert, C. (2013). Dialogical perspectives on aided communication. In N. Noren, C. Samuelsson, \& C. Plejert (Eds.), Aided communication in everyday interaction (pp. 1-22). Guildford: J \& R Press Ltd.

Noren, N., Svensson, E., \& Telford, J. (2013). Participants' dynamic orientation to folder navigation when using a VOCA with a touch screen in talk-in-interaction. Augmentative and Alternative Communication, 29, 20-36. doi:10.3109/07434618.2013.767555 
Pullin, G., Treviranus, J., Patel, R., \& Higginbotham, J. (2017). Designing interaction, voice, and inclusion in AAC research. Augmentative and Alternative Communication, 33, 139-148. doi: 10.1080/07434618.2017.1342690

Sacks, H., Schegloff, E. A., \& Jefferson, G. (1974). A simplest systematics for the organization of turn-taking for conversation. Language, 50, 696-735.

Savolainen, I. (2010, August). TAIKE. A large set of dynamic displays and a new communication system. Paper presented at the ISAAC Conference in Barcelona.

Schegloff, E. A. (1996). Turn organization: One intersection of grammar and interaction. In E. Ochs, E. A. Schegloff, \& S. A. Thompson (Eds.), Interaction and grammar (pp. 52-113). Cambridge: Cambridge University Press.

Schegloff, E. A. (2007). Sequence organization in interaction. Cambridge: University Press.

Sigurd Pilesjö, M. (2013). On the use of bodily action and vocalizations as recourses and methods when claiming and completing turns in aided interaction. In N. Noren, C. Samuelsson, \& C. Plejert (Eds.), Aided communication in everyday interaction (pp. 5994). Guildford: J \& R Press.

Sundqvist, A., Plejert, C., \& Ronnberg, J. (2010). The role of active participation in interaction for children who use augmentative and alternative communication. Communication and Medicine, 7, 165-175. doi:10.1558/cam.v7i2.165

Ten Have, P. (2007). Doing conversation analysis. London: SAGE.

VISK = Auli Hakulinen, Maria Vilkuna, Riitta Korhonen, Vesa Koivisto, Tarja Riitta Heinonen \& Irja Alho (2004) : Iso suomen kielioppi. [Big Finnish grammar] Helsinki: Suomalaisen kirjallisuuden seura. Retrieved from: http://scripta.kotus.fi/visk 10.1.2019 
von Tetzchner, S., \& Basil, C. (2011). Terminology and notation in written representations of conversations with augmentative and alternative communication. Augmentative and Alternative Communication, 27, 141-149. doi:10.3109/07434618.2011.610356 


\author{
Appendix A \\ Transcript Notation \\ Transcription of spoken and aided utterances applied the traditional CA conventions by Jefferson \\ (2004) and AAC conventions by von Tetzchner and Basil (2011). \\ 1st $\quad$ First part of turn-transition \\ 2nd $\quad$ Second part of turn-transition \\ 3rd Third part of turn-transition \\ $\rightarrow \quad$ Aided first pair part \\ Time in seconds. \\ Natural speech Naturally spoken elements, translations are under the original language \\ Fall in intonation. \\ $\lceil$ Overlap between multiple lines. \\ 1 \\ \lfloor\rfloor \\ $><\quad$ Talk is quicker than surrounding talk. \\ $€ € \quad$ Smile in the voice. \\ "Synthesized speech" Utterances produced with an SGD. \\ * $\quad$ Aided communicator activates the cell of an SGD. \\ Gaze Gaze is transcribed with capital letters referring to the participants and \\ arrows in positions, in which the direction of the gaze changes. \\ For example: $((\mathrm{M} \rightarrow \mathrm{J}))$ Mother looks Jaakko \\ For example: $((\mathrm{M} \leftrightarrow \mathrm{J}))$ Mother and Jaakko look at each other
}

